OPEN ACCESS

Edited by:

Vinita Agarwal,

Salisbury University, United States

Reviewed by:

Monica Pivetti,

University of Bergamo, Italy

Michael J. Deml,

Université de Genève, Switzerland

*Correspondence:

Øyvind Ihlen

oyvind.ihlen@media.uio.no

Specialty section:

This article was submitted to

Health Communication,

a section of the journal

Frontiers in Communication

Received: 19 April 2021

Accepted: 17 June 2021

Published: 30 June 2021

Citation:

Ihlen $\varnothing$, Toledano M and Just SN (2021) Using Rhetorical Situations to

Examine and Improve

Vaccination Communication.

Front. Commun. 6:697383.

doi: $10.3389 /$ fcomm.2021.697383

\section{Using Rhetorical Situations to Examine and Improve Vaccination Communication}

\author{
Øyvind Ihlen ${ }^{1 *}$, Margalit Toledano ${ }^{2}$ and Sine Nørholm Just $^{3}$ \\ ${ }^{1}$ University of Oslo, Oslo, Norway, ${ }^{2}$ University of Waikato, Hamilton, New Zealand, ${ }^{3}$ Roskilde University, Roskilde, Denmark
}

Opinion polls have documented a considerable public skepticism towards a COVID-19 vaccine. Seeking to address the vaccine skepticism challenge this essay surveys the research on vaccine hesitancy and trust building through the lens of the rhetorical situation and points towards five broad principles for a content strategy for public health communicators in regards to vaccination: 1) vaccine hesitancy is not irrational per se; 2) messages should be tailored to the various hesitancy drivers; 3) what is perceived as trustworthy is situational and constantly negotiated; 4) in areas of uncertainty where no exact knowledge exists, the character of the speaker becomes more important; and 5) the trustworthiness of the speaker can be strengthened through finding some common ground-such as shared feelings or accepted premises-with the audience. Such common insights are on offer in the literature on rhetoric and persuasion and linked here with the research on vaccine communication and trust focusing specifically on the latter and character.

Keywords: vaccine communication, trust, rhetoric, vaccine hesitancy, COVID-19

\section{INTRODUCTION}

Opinion polls as well as scholarly studies consistently show a considerable hesitancy towards vaccination in general and towards a COVID-19 vaccine (Tyson et al., 2020; Williams et al., 2020). Indeed, one international survey showed a drop in the numbers that said they would get a COVID-19 vaccine if available (from $77 \%$ in July to $73 \%$ in October; $N=18,000$ ) (Ipsos, 2020). Similarly, another international survey indicated that $14.2 \%$ disagreed somewhat or completely with the statement "Accept COVID-19 vaccine if generally available," while $14.2 \%$ were neutral or had no opinion ( $\mathrm{N}=$ 13,426), leading to the conclusion that "the current levels of willingness to accept a COVID-19 vaccine are insufficient to meet the requirements for community immunity" (Lazarus et al., 2020).

In general, "effective communication strategies are important to engage policy-makers and communities in prevention and control efforts, and to increase buy-in and confidence" (World Health Organization (WHO), 2019, p. 2 and 10). Southwell et al., (2020) argued that approaches to COVID-19 vaccination are rooted in past beliefs and attitudes towards vaccination. Based on findings from a survey that was conducted in the United States in April 2020 by RTI International they concluded that "communication professionals preparing to encourage COVID-19 prevention should recognize that audiences are not blank slates. Popular perceptions of infectious disease offer part of the foundation on which new conversations with audiences will rest" (p. 1708).

In this essay we explore communicative approaches that health communicators can use to increase vaccination rates. To do so, we turn to theory that may assist in the development of persuasive content strategies. First we discuss the literature on vaccine hesitancy. Unlike studies in 
this tradition (e.g., Chou and Budenz, 2020; Xu et al., 2020), however, we want to focus on the situational character of the appropriate communication strategies. As acknowledged by much persuasion research, context is a complicating factor for persuasion attempts (O'Keefe, 2016; Perloff, 2010). Thus, we use the notions of "the rhetorical situation" (Bitzer, 1968) to generate insights for content strategies that build trust in health authorities, generally, and vaccination programs, more specifically. This notion offers a systematic understanding of both the rhetorical constraints and possibilities in the situation that public health authorities find themselves in when communicating about vaccines. Five communication principles are deduced from our analysis of the rhetorical situations of vaccine communication and related to the literature on trust and character. While the authorities need to use "everything that is available" (Burke, 1941/1973, p. 23), be it logical or emotional appeals, we foucs in partiuclar on the importance of source related aspects.

\section{VACCINE HESITANCY}

There is a considerable literature on vaccine hesitancy (Hickler et al., 2015; Jarrett et al., 2015; Larson et al., 2018; Thomson et al., 2018; Kowalska et al., 2019; Jenkins and Moreno, 2020; Machado et al., 2020; Sun et al., 2020). Within this literature, several recommendations for vaccination communication strategies have also been formulated, both in white paper formats (European Centre for Disease Prevention and Control, 2009) and in scientific journals (Goldstein et al., 2015; Thomson et al., 2018; Jenkins and Moreno, 2020). The emergent conclusions are that "multicomponent and dialogue-based interventions," like involvement of religious or community leaders, are most effective (Jarrett et al., 2015, p. 4180). Further, the role of emotions has been discussed (Chou and Budenz, 2020; Sun et al., 2020), suggesting that authorities could appeal to positive emotions such as helping the community. In addition, raising awareness of "the manipulation of negative emotions by disinformation campaigns may help to inoculate against the effects of vaccine misinformation" (Chou and Budenz, 2020, p. 3).

Discussions have also centered on the notion of "health literacy"-the ability to "obtain, process, understand, and communicate about health-related information needed to make informed health decisions" (Berkman et al., 2010, p. 16). While some citizens do seek out "neutral" information, it has also become evident that "people select more belief-consistent information compared to belief-inconsistent information and perceived belief-confirming information as being more credible, useful, and convincing" (Meppelink et al., 2019, p. 129). Surprisingly, "biased selection and biased perceptions of message convincingness were more prevalent among people with higher (health literacy)“ (Meppelink et al., 2019, p. 129). This implies that the challenge for health authorities is not only the selection of the most relevant information but the effort to convince those that are hesitant of the credibility of this information. Here, emotional factors, like suspicion and trust, play major roles in the resistance to vaccination, and appeals to the cognitive faculty of health literacy might not provide the most effective solution.

Finally, the literature has taken on the question of what drives vaccine hesitancy, pointing to a whole slate of different drivers related to complacency, convenience and confidence (MacDonald and Sage Working Group on Vaccine Hesitancy, 2015). The latter factor implies a lack of trust in authorities, which is also highlighted by other studies that point to the importance of trust in "the ability of the government" to handle health crises (Deurenberg-Yap et al., 2005; Mesch and Schwirian, 2015). Indeed, calls have been issued to study trust in public authorities and medical experts in relation to health communication (Cummings, 2014), vaccine hesitancy (Kestenbaum and Feemster, 2015) as well as normative beliefs in relation to information sources on COVID-19 (Rimal and Storey, 2020). Trust in institutions can be influenced by people's perception of institutional characteristics and how an institution comes across as trustworthy (Chryssochoidis et al., 2009; Renn, 2009). Findings in the literature point to how social actors appear to be trustworthy (or not) based on others' perceptions of their competence, expertise, knowledge, objectivity, fairness, consistency, sincerity, caring, empathy, compassion and goodwill (Covello, 2009; Guy et al., 2013). Regarding vaccine and vaccine hesitancy, the role of source credibility and strategies to strengthen such credibility are singled out as appealing to expertise, trustworthiness and caring/goodwill (Xu et al., 2020). The latter strategies have been culled from the literature on persuasion and rhetoric, and we now turn to a concept squarely rooted in the latter tradition which we argue is very useful for the purpose at hand-improving vaccine communication.

\section{THE (NEW) RHETORICAL SITUATION}

The rhetorical situation serves as a framework to discuss the constraints on and possibilities for content strategies regarding public authorities' initiatives to build trust in vaccine programs and, hence, counter vaccine hesitancy.

Bitzer (1968) coined the concept and provided the following definition:

Rhetorical situation may be defined as a complex of persons, events, objects, and relations presenting an actual or potential exigence which can be completely or partially removed if discourse, introduced into the situation, can so constrain human decision or action as to bring about the significant modification of the exigence. (p. 6).

A rhetorical situation has three constitutive elements-exigence, audience and constraints. The rhetor must define and grasp the exigence-or problem to be solved-with words and identify an audience that potentially can help solve the problem. Importantly, the rhetor needs to understand the constraints in the situation and what rhetorical strategies are required to overcome these and realize the rhetor's aim. While the concept of the rhetorical situation has been very influential in the field, scholars of rhetoric have also expressed doubts about its deterministic tendencies (Vatz, 1973; Jasinski, 2001). It has been 
argued that rather than only answering to particular situational needs by adapting to situational requirements the rhetor can also identify possibilities on offer in each situation. In the following, we begin from Bitzer's original framework but tweak it for our purpose and seek to integrate both situational limitations and opportunities, using the insights from the preceding sections as starting points for a discussion of the rhetorical situation of vaccine hesitancy.

\section{The Problem}

The first element of a rhetorical situation is a pressing problem ("exigence"); a matter that calls for and can be solved with the help of rhetoric. The problem may be latent, and there is no guarantee that it will be solved once and for all. The pressing problem is, nonetheless, the organizing principle for a situation; it specifies the audience and the change that is desired. We maintain that the lack of trust in vaccines forms a rhetorical problem. That is, when offering, for instance, COVID-19 vaccines, public health authorities encounter lack of trust in the vaccines. This lack of trust requires a rhetorical response to-why should the vaccine be trusted? The introduction of a vaccine needs to be accompanied by some kind of discourse. The public health authorities need to say something to address the lack of trust harbored by some people, although it could be argued that the lack of trust-the exigence-is not entirely solvable through rhetoric. We maintain, however, that the rhetorical situation can be usefully extended to include a focus on an exigence that is at least is potentially and partly modified through rhetoric. This, we argue, is especially the case for those that are not necessarily ardent vaccine skeptics or conspiracy believers, but have second thoughts about, for instance, the possible side effects of a newly introduced vaccine. Again, we believe, trust plays a role.

A common definition of trust points to how it is "a psychological state comprising the intention to accept vulnerability based upon positive expectations of the intentions or behavior of another" (Rousseau et al., 1998, p. 395). At the individual level, trust is seen as either relational, between the trusting person and the other, or as calculative (confidence), based on the others' past actions or expectations tied to future actions (Earle, 2010). At the societal level, trust is a social mechanism that reduces complexity and uncertainty (Luhmann, 1993). Trust is frequently mentioned as a key component for risk responses (Renn, 1998; Palenchar et al., 2017) that can amplify or attenuate citizens' reactions to perceived public risks (Kasperson et al., 1988).

In the context of trust in vaccination, it is relevant to mention McAllister, (1995) distinction between cognitive and affective foundations of interpersonal trust. Cognition-based trust relates to evidence of trustworthiness whereas the affective foundation of trust denotes emotional orientations. Further, institution-based trust can be distinguished as a particular and important trust variable. Trust in institutional performance is important for risk response, as high levels of institution-based trust is indicative of resilient societies that can "resist, absorb, accommodate to and recover from the effects of a hazard in a timely and efficient manner, including through the preservation and restoration of its essential basic structures and functions" (United Nations Office of Disaster Risk Reduction (UNISDR), 2009, p. 24).

Institutional trust in this context can also be tied to epistemic trust-trust in science or technology-which is essential for understanding and reacting to risk (Veland and Aven, 2013). If experts are divided in their views on risk estimates, as is often emphasized in news media reports on risk assessments, greater amounts of trust are needed. Many risk situations are also complicated by how a range of institutions at various geographical and administrative levels are involved.

Bringing these different perspectives together to take risk bearers' institutional and epistemic trust-levels as well as their cognitive and emotional orientation to the risk into account is vital for health communication. To strengthen trust, we must thoroughly understand the concept and its drivers. Of particular importance is the sociological assumption that trust is a social construct that has to be analyzed in particular sociocultural and political contexts (Weber and Carter, 2003). As trust is relative to expectations tied to, for instance, professional roles, the public expects certain behaviors of the authorities in risk situations (Chryssochoidis et al., 2009).

Research shows that public trust in vaccines and immunization has declined in Western developed countries (Dubé et al., 2013; Yaqub et al., 2014). Crucially, the literature emphasizes how communication alone is not going to stop the spread of diseases, but may help alleviate citizens' distrust in or dissent to the advice of public health authorities (Kennedy, 2019). This, then, is the specific rhetorical problem in the current situation--the lack of confidence in vaccines, specifically, and the advice of health authorities, more generally. Some countries (e.g., the United States and Australia) have addressed the basic problem of lack of immunization through compulsory vaccination. In other countries (e.g., Sweden, Norway, Denmark, the Netherlands, United Kingdom), "compulsory immunization is unlikely to be acceptable and indeed high coverage has been achieved through other approaches" (Miller, 2015 , p. 267). In other words, rhetoric plays a more important role in these countries, as citizens must be persuaded rather than coerced.

\section{The Audience}

The second element in the rhetorical situation is the audience, whose thoughts, decisions, or actions the rhetor aims to change in order to resolve the exigence. The audience must agree that something is a problem, namely, that there is a certain imperfection that needs to be resolved. In risk communication, the audience must trust the risk communicators when they say there is a risk and that the proposed solution is preferable. Again, the issue of trust is at the center, and the chosen rhetorical utterance can lead the audience to in- or decrease its trust in the communicating organization(s). In the context of this paper, the audience is the group of people that, according to the health authorities, should either get vaccinated themselves or should vaccinate their children, but is hesitant.

Hesitancy regarding vaccination can be spread on a continuum, ranging from full acceptance to outright refusal of all vaccines (MacDonald and Sage Working Group on Vaccine 
Hesitancy, 2015). It seems to be a reasonable assumption that the further towards the right side of the continuum ("refuse all"), the more difficult the rhetorical challenge is. Indeed, the "refuse all"position may fall outside of the rhetorical audience, as they are unwilling to change their mind. Similarly, the "full acceptance"position need not be persuaded, as it is already in agreement with the authorities' view. That said, this latter group may constitute a specific audience in the current situation, as demands for faster development and implementation of a COVID-19 vaccine may serve to complicate matters and exacerbate the more skeptic audiences.

According to Paterson et al. (2016), a particularly salient audience group consists of hesitant health care providers, mainly general practitioners and nurses. As health care providers constitute "one of the strongest influencers in vaccination decisions" (Paterson et al., 2016, p. 6701), strengthening the trust between them, the health authorities and policy makers is particularly pressing-indicating how the rhetorical situation is sometimes complicated because one has to address an intermediate audience as a means of reaching one's ultimate aim. In this case, to persuade hesitant risk bearers to comply with vaccine recommendations (this topic merits its own discussion, which is beyond the scope of this paper suffice to say that we cannot assume that health care providers promote vaccination).

\section{Constraints and Strategic Possibilities}

The third element in the rhetorical situation is constraints-obstacles which the rhetor must overcome (and opportunities to be leveraged) to successfully solve a problem. Constraints can be rhetorical, physical, or cultural. The constraints impose limits on and, significantly, shape what the rhetor can say and do. Constraints, then, are conditions of possibility, and in the following discussion we will emphasize how they can be handled strategically.

The first, and most obvious, constraint for health authorities is that they cannot take trust for granted. As mentioned, there are a number of reasons for the fragility/decline of trust, in the context of vaccine hesitancy. However, the "axiomatic" tendency of scholars and practitioners alike has been to treat "vaccine hesitancy as ignorant or irrational" (Kennedy, 2019, p. 4). This is not necessarily the case, as pointed out by some scholars. Most importantly, there is reason to differentiate between different forms of vaccine hesitancy-from accepting some, to rejecting all (MacDonald and Sage Working Group on Vaccine Hesitancy, 2015). It is necessary to understand and recognize the anxiety and helplessness that vaccine hesitants are feeling when facing powerful health institutions and the pharma industry that is authorized to take decisions affecting theirs or their children's health. Further, even if a hesitant position is unreasonable, one does not persuade anybody to give up that position by denigrating it.

Another weakness of pro-vaccination communication is a tendency towards over-reliance on information, the cognitive foundation of trust. Based on an analysis of government vaccination campaigns in Australia, McKinnon and Orthia, (2017) stated that:
(M)odern campaigns rely primarily on scientific fact, whereas 200 years ago personal stories and emotional appeals were more common. We argue that the return to the old ways may be needed to address vaccine hesitancy around the world. (p. 1).

Echoing this turn to tradition, the strategic possibility of involving religious leaders or community leaders in promoting vaccination has been pointed out. Such leaders, it is argued, would lend affective as well as cognitive credibility to official recommendations (Jarrett et al., 2015, p. 4180).

Next, in order to become persuasive, communicators must take into account the audience's specific reasons for vaccine hesitancy, which:

May involve alternative understandings of health, different perspectives of parental responsibility, or questioning the legitimacy of traditional authorities. These discourses exemplify postmodern tensions in society, making the antivaccination issue one of significant complexity. (Kata, 2010, p. 1715, p. 1715).

More philosophically, Kata (2010) argues that "Postmodernism does not accept one source of "truth"” and that this is "a philosophy adopted by the anti-vaccination movement" that enables "vaccine objectors (to) reject the "facts" presented to persuade them towards vaccination; for the anti-vaccination movement, "mis" information is simply their version of information" (p. 1715).

For Lee and Male (2011), major anti-vaccination themes link to elements of the anti-consumption movement: religion; ideological oppositions; freedom of choice/freedom from harm; the cost-benefit trade-off of risk assessment; and feelings of uncertainty, confusion and contradictions. Other studies position vaccine hesitancy as part of a larger phenomenon of "denialism" (Dubé et al., 2013, p. 1766), or subsume it under the erosion of public trust in institutions as a social trend (Yaqub et al., 2014). Relying on an extensive review of empirical literature published in English after 2009, as well as data from market research, Yaqub and colleagues (2014) have identified "a range of reasons for vaccination attitudes" (p. 1) and find that only some of them "can be characterized as being related to lack of awareness or misinformation. Reasons that relate to issues of mistrust are cited more commonly in the literature than issues that relate to information deficit" (p. 1). This comprehensive literature review detailed major reasons for hesitancy, including: "Distrust of government sources, perceived low severity of illness, perceived ineffectiveness of vaccine, fear of needles/pain of vaccination, perceived low risk of contracting illness, and mainly, fear of side effects and vaccine safety" (p. 4). Research has also shown how "balanced" news reports concerning a possible link between autism and vaccination caused uncertainty and led people to believe that experts were divided on the matter (Dixon and Clarke, 2012).

The level of trust in institutions in a specific country will also form a constraint or a possibility for risk communication on vaccines. Large levels of trust in authorities make it easier to communicate about vaccination, whereas authorities in countries with very little trust experience more problems (Edelman, 2019). In this vein, survey research has compared the perceived effectiveness of vaccines by regions and countries, placing 
France and Liberia as outliers, the former with many people considering vaccines to be unsafe and the latter perceiving them as safe (Wellcome Global Monitor, 2018). Thus, the rhetorical challenge for health authorities seems larger in France than in Liberia. That is, while attitudes towards vaccination form a constraint in France, they seem to be an opportunity in Liberia. The survey pointed to how the level of French skepticism did not vary significantly when controlled for such variables as education or age. One possible explaining factor is the 2009 swine flu vaccination program, which was fraught with scandals and accusations that the WHO was influenced by pharmaceutical companies.

Further, the changed fragmented media landscape presents a constraint, something that has been discussed quite extensively in the context of health communication in general (Ho et al., 2013; Walter et al., 2020). Several studies have focused on the rise of anti-vaccination groups on the Internet (Kata, 2012; Hoffman et al., 2019). It has been commented that the "dissenting voices have become highly connected networks, undermining one of the most effective disease prevention tools" (Larson, 2018, p. 2245). The changed media landscape is seen as providing a fertile ground for skepticism and poses challenges for public risk communication. The competition for attention is fierce and lengthy, complex arguments do not fare well. Tried and tested rhetorical strategies of risk communication (Heath \& O'Hair, 2009) come under pressure when appeals to emotions and personal beliefs dominate in fragmented social media "bubbles" or "echo chambers" where people seek to get their views confirmed without being exposed to counter arguments (Colleoni et al., 2014; Del Vicario et al., 2016).

On the positive side, the potential for two-way communication on social media can help build trust and enhance self-efficacy, which is crucial for risk bearers' perception of and response to their situation (Paton, 2007; Stephens and Malone, 2012). Furthermore, the use of credible spokespersons on social media can be a useful strategy for creating institutional trust, pointing to the importance of factors such as competence, expertise, knowledge, objectivity, fairness, consistency, sincerity, caring, empathy, compassion and goodwill (Renn and Levine, 1990; Covello, 2009; Guy et al., 2013). When using social media, it is much easier to create identification than it is through traditional public relations material like brochures or letters. However, a multicomponent strategy is likely to be the most effective (Jarrett et al., 2015, p. 4180). It is also possible for health authorities to intervene in social media and remind actors about available research material on specific issues.

\section{CONSEQUENCES FOR CONTENT STRATEGIES}

Viewing the research on vaccine hesitancy and trust building through the lens of the rhetorical situation points towards five broad principles for a content strategy on vaccination: A first point is that vaccine hesitancy is not irrational per se. Taking concern seriously is, as mentioned, a key lesson from risk communication if the goal is to build trust (Renn, 2009). The drivers for vaccine hesitancy are fairly well understood, as several cross-country studies have been conducted on how vaccines are perceived (Yaqub et al., 2014; Larson et al., 2016). Content strategies need to be related to the most important drivers for hesitancy in their contexts, be it religious views, skepticism of "big pharma," first- or secondhand experience with side effects of vaccines, or a general mistrust in authorities. The larger issue of distrust in elites and experts, is underpinned by "political disenfranchisement and economic marginalisation" that probably no rhetorical strategy can do away with on its own (Kennedy, 2019). Health care personnel should be made aware of this, as well as of the fact "that experts and non-experts perceive risk differently" (Sanftenberg et al., 2021, p. 195). Taking the perceptions and feelings of people seriously, rather than dismissing them is a key insight that needs to be repeated as pointed out by several scholars (e.g., Hobson-West, 2007; Hausman, 2019; Pivetti et al., 2020).

Second, and as a consequence of the many different motives and drivers for hesitancy, and, indeed, the many different degrees of hesitancy, one-size fits all-messages are unlikely to succeed. Furthermore, the literature on vaccine hesitancy has warned against using a content strategy that "too strongly advocates vaccination" (Dubé et al., 2015, p. 4200), and it is emphasized that attempts "to increase concerns about communicable diseases or correct false claims about vaccines may be especially likely to be counterproductive" (Nyhan et al., 2014, p. e835). Similarly, it is argued that aggressive pro-vaccination messages can be counterproductive (Jenkins and Moreno, 2020). Thus, tailoring messages to different hesitancy drivers is a guiding strategic communication principle for all health communication. A recent experimental survey argued that framing the issue as a matter of personal and collective health risk had a positive effect (Motta et al., 2021). The herd community argument has been shown to reduce vaccine hesitancy in other populations too (Schwarzinger et al., 2021).

Third, it is necessary to understand that perceptions of trustworthiness are situational and constantly negotiated. Most notably, trust can be influenced by people's perception of institutional characteristics and how an institution comes across as trustworthy (Chryssochoidis et al., 2009; Covello, 2009; Renn, 2009). This insight echoes ancient writings on ethos, which provides guidelines on how the trustworthiness of the speaker may be strengthened through demonstration of practical wisdom, virtue and goodwill (Aristotle, trans. 2007). Since ethos is an attitude in the audience towards a rhetor (a communicator) at any point in time, communicators should seek to tap into the dynamic relationship between trust as expert-systems and credibility (ethos) in a rhetoricalsituational sense, where the last creates the first, and the first may influence how we experience communicators. This means that ethos is not (really) a fixed quality in a sender or a text but is constantly negotiated, which might help explain the negative findings of $\mathrm{Xu}$ and colleagues (2020) in their test of messages "designed to convey the expertise, trustworthiness, or caring/goodwill of a governmental source of information" (p. 1). While communicators must do their best to build trust, the audience's evaluation of their effort is highly contextual (Perloff, 2010; O'Keefe, 2016).

Relatedly, the fourth point is that since rhetoric deals with areas where no exact knowledge exists, the character of the speaker becomes important. As lay persons with no medical training or 
insight into epidemiological matters, it is hard to follow arguments about, for instance, the safety of the vaccines. In general, rational appeals to logos, and the concomitant specific arguments built on available rationalities, have become increasingly complex and difficult to understand, therefore audiences are forced to trust communicators to an ever greater extent. That is, when we do not understand the matters at hand, we must base our actions on other people's advice. Ethos, or character, can trump logos, as we do not necessarily have access to valid logical arguments or adhere these, while we have to either trust or not trust the communicator (Baumlin and Scisco, 2018). As the literature will attest to, we might react positively to a message due to the a number of different reasons, but "the source factors with the most immediate (if complex) effects on persuasive outcomes are credibility and liking" (O'Keefe, 2016, p. 155). Thus, having credible spokespersons, with whom the audience can easily identify, can be a crucial strategy, also for creating institutional trust. As recommended by others "Public health agencies can use photographs and quotes from role models, such as community leaders, celebrities, elected officials, and health care providers" getting vaccinated (Quinn et al., 2020, p. 357). Public health authorities are advised to engage in "expectation management" concerning priorities, to express cautious optimism and to let trusted local health care personnel administer the vaccine (Warren and Lofstedt, 2021). Similarly, the trustworthiness of the institution might be enhanced through transparency concerning data and the uncertainty surrounding all vaccines (Quinn et al., 2020; Offerdal et al., 2021). And, finally, emphasizing the role of an expert network is seen as crucial, in part as setting up multi-disciplinary teams (Sanftenberg et al., 2021), but also in demonstrating that a whole range of experts are in support (Kjeldsen et al., in press).

A fifth principle is that there is an indirect route to strengthening ethos that depends on understanding the audience: Emotional appeals, pathos, may strengthen ethos and, similarly, using enthymemes and maxims-certain logical appeals-can work well because audiences "are pleased if someone in a general observation hits upon opinions that they themselves have about a particular instance" (Aristotle, trans. 2007.21.15). Communicators are urged to consider the predispositions and values of the audience so as to adapt to what is important to the recipients of one's message (Chou and Budenz, 2020). Research on parenting blogs, for instance, have concluded that "parents against vaccination may be versed in supporting literature they believe to be credible" (Jenkins and Moreno, 2020, p. 241). In other words, when attempting to strengthen ethos, the rhetor should not only consider the topic and the rhetor him- or herself, but also the audience (Xu et al., 2020). In communication on climate change, for instance, it is urged that communicators should relate to people's different ethical, ideological and political beliefs, as well as different historical interpretations and competing visions for the future (Hulme, 2009). This insight is equally valid for vaccine communication, and tying in with visions that parents hold about the future and wellbeing of their children, as well as other emotionally powerful beliefs of the audience, could be a beneficial strategy for communication about vaccine hesitancy.
This should not, however, be thought of as pandering to the audience, but rather seeking to identify some common ground between the communicator and the audience, which is a basic ancient communication principle. Qualitative research as well as text mining of social media can assist in understanding the link between peoples identity and vaccination intent (Wood and Schulman, 2021). Conservative or right-wing political ideology has been seen as contributing negatively in this regard (i.e., Baumgaertner et al., 2018; Broniatowski et al., 2020; Rabinowitz et al., 2016). Again, a recommendation is to partner with opinion leaders that are trusted by this particular group.

\section{CONCLUSION}

Taken together, this essay indicates how trust is negotiated in a hybrid media ecology where traditional epistemic positions are challenged and points to the practical consequences of such negotiation, thereby indicating useful content strategies for public health authorities who wish to address vaccine hesitancy. A first, and obvious, conclusion from the literature review is that vaccine hesitancy should not be treated as a completely irrational behavior to be ridiculed until everyone behaves. Rather than attempting to win over the "hearts and minds" of hesitant audiences, mandatory vaccination could, in some cases, be the only viable solution (Miller, 2015; McCoy, 2019). Still, with consistent high levels of trust in vaccination in a range of countries, it seems that the goal of compliance is often obtainable without legal measures. That is, rhetoric has a central role to play-also when used in combination with compulsory initiatives, as the case of COVID-19 reminds us.

This essay has applied the notion of the rhetorical situation in order to highlight how rhetoric may best fulfill the goal of building trust in contested public health advice, using the case of vaccine hesitancy as our recurrent example. We regard the lack of trust as an exigence which is at least partly rhetoricalthe public health authorities can weigh in with rhetoric and potentially persuade at least those sitting on the fence. Here we have particularly focused on character.

Drawing from existing literatures we have analyzed the current situation and pointed to common principles for content strategies that might support a "fitting response" to vaccine hesitancy. This list of suggestions is certainly not exhaustive, but it does provide a starting point for empirical testing and further theorization. In particular, more research is needed to reflect how the mentioned changes in the media landscape call for a revised conceptualization of the rhetorical situation as well as modified strategies to achieve fitting responses in practice.

In the current context, it is very difficult to assume (or construct) a clearly demarcated rhetorical situation (Edbauer, 2005), meaning no fixed or generalized rules can be spelled out. Thus, we encounter a paradox between the practical need for generalizations and theoretical calls for specification. That is, while the principles for content strategies we have presented here are all theoretically backed, they offer no guarantees. Our suggestions, in sum, reproduce rather than resolve the 
inherent situationality of situations; they may be generally sound, but will only work in the specific situation if they are adequately adapted to it. More research is needed to address if not, indeed, overcome this inherent limitation.

\section{DATA AVAILABILITY STATEMENT}

The original contributions presented in the study are included in the article/supplementary material, further inquiries can be directed to the corresponding author.

\section{REFERENCES}

Aristotle, trans., and Kennedy, G. A. (2007). On Rhetoric: A Theory of Civic Discourse. 2 ed.. New York: Oxford University Press.

Baumgaertner, B., Carlisle, J. E., and Justwan, F. (2018). The Influence of Political Ideology and Trust on Willingness to Vaccinate. PLoS One 13 (1), e0191728. doi:10.1371/journal.pone.0191728

Baumlin, J. S., and Scisco, P. L. (2018). "Ethos and its Constitutive Role in Organizational Rhetoric," in Handbook of Organizational Rhetoric and Communication. Editors $\varnothing$. Ihlen and R. L. Heath (Malden, MA: (Wiley Blackwell), 201-213. doi:10.1002/9781119265771.ch14

Berkman, N. D., Davis, T. C., and McCormack, L. (2010). Health Literacy: What Is it?. J. Health Commun. 15 (Suppl. 2), 9-19. doi:10.1080/ 10810730.2010.499985

Bitzer, L. F. (1968). The Rhetorical Situation. Philos. Rhetoric 1 (1), 1-14.

Broniatowski, D. A., Quinn, S. C., Dredze, M., and Jamison, A. M. (2020). Vaccine Communication as Weaponized Identity Politics. Am. J. Public Health 110 (5), 617-618. doi:10.2105/AJPH.2020.305616

Chou, W.-Y. S., and Budenz, A. (2020). Considering Emotion in COVID-19 Vaccine Communication: Addressing Vaccine Hesitancy and Fostering Vaccine Confidence. Health Commun. 35, 1718-1722. doi:10.1080/ 10410236.2020.1838096

Chryssochoidis, G., Strada, A., and Krystallis, A. (2009). Public Trust in Institutions and Information Sources Regarding Risk Management and Communication: Towards Integrating Extant Knowledge. J. Risk Res. 12 (2), 137-185. doi:10.1080/13669870802637000

Colleoni, E., Rozza, A., and Arvidsson, A. (2014). Echo Chamber or Public Sphere? Predicting Political Orientation and Measuring Political Homophily in Twitter Using Big Data. J. Commun. 64 (2), 317-332. doi: $10.1111 /$ jcom. 12084

Covello, V. T. (2009). "Strategies for Overcoming Challenges to Effective Risk Communication," in Handbook of Risk and Crisis Communication. Editors R. L. Heath and D. O'Hair (London: (Routledge), 143-167.

Cummings, L. (2014). The“Trust"Heuristic: Arguments from Authority in Public Health. Health Commun. 29 (10), 1043-1056. doi:10.1080/ 10410236.2013.831685

Del Vicario, M., Vivaldo, G., Bessi, A., Zollo, F., Scala, A., Caldarelli, G., et al. (2016). Echo chambers: Emotional Contagion and Group Polarization on Facebook. Sci. Rep. 6, 37825. doi:10.1038/srep37825

Deurenberg-Yap, M., Foo, L. L., Low, Y. Y., Chan, S. P., Vijaya, K., and Lee, M. (2005). The Singaporean Response to the SARS Outbreak: Knowledge Sufficiency versus Public Trust. Health Promot. Int. 20 (4), 320-326. doi:10.1093/heapro/dai010

Dixon, G. N., and Clarke, C. E. (2012). Heightening Uncertainty Around Certain Science. Sci. Commun. 35 (3), 358-382. doi:10.1177/1075547012458290

Dubé, E., Gagnon, D., and MacDonald, N. E. and Sage Working Group on Vaccine Hesitancy (2015). Strategies Intended to Address Vaccine Hesitancy: Review of Published Reviews. Vaccine 33 (34), 4191-4203. doi:10.1016/ j.vaccine.2015.04.041

Dubé, E., Laberge, C., Guay, M., Bramadat, P., Roy, R., and Bettinger, J. A. (2013). Vaccine Hesitancy. Hum. Vaccin. Immunother. 9 (8), 1763-1773. doi:10.4161/ hv.24657

\section{AUTHOR CONTRIBUTIONS}

All authors listed have made a substantial, direct, and intellectual contribution to the work and approved it for publication.

\section{FUNDING}

The study was funded by the Research Council of Norway through the programme SAMRISK. The publication is tied to the research project called "Pandemic Rhetoric" (PAR) (296347).

Earle, T. C. (2010). Trust in Risk Management: A Model-Based Review of Empirical Research. Risk Anal. 30 (4), 541-574. doi:10.1111/ j.1539.6924.2010.01398.x

Edbauer, J. (2005). Unframing Models of Public Distribution: From Rhetorical Situation to Rhetorical Ecologies. Rhetoric Soc. Q. 35 (4), 5-24. doi:10.1080/ 02773940509391320

Edelman (2019). Annual Edelman Trust Barometer [i Perm for Ethos]. United States: Edelman.

European Centre for Disease Prevention and Control (2009). Influenza Communication Guide: How to Increase Influenza Vaccination Uptake and Promote Preventive Measures to Limit its Spread. European Union: European Centre for Disease Prevention and Control.

Goldstein, S., MacDonald, N. E., Guirguis, S., and Sage, Working. (2015). Group on Vaccine Hesitancy Health Communication and Vaccine Hesitancy. Vaccine 33 (34), 4212-4214. doi:10.1016/j.vaccine.2015.04.042

Guy, M. E., Newman, M. A., and Emel Ganapati, N. (2013). Managing Emotions while Managing Crises. Intl Jnl Emerg. Serv. 2 (1), 6-20. doi:10.1108/ijes-072012-0033

Hausman, B. L. (2019). Anti/Vax: Reframing the Vaccination Controversy. New York: ILR Press/Cornell University Press. doi:10.7591/9781501735639

Hickler, B., Guirguis, S., and Obregon, R. (2015). Vaccine Special Issue on Vaccine Hesitancy. Vaccine 33 (34), 4155-4156. doi:10.1016/j.vaccine.2015.04.034

Ho, S. S., Scheufele, D. A., and Corley, E. A. (2013). Factors Influencing Public Risk-Benefit Considerations of Nanotechnology: Assessing the Effects of Mass media, Interpersonal Communication, and Elaborative Processing. Public Underst Sci. 22 (5), 606-623. Available at: http://www.ncbi.nlm.nih.gov/ pubmed/23833174 doi:10.1177/0963662511417936

Hobson-West, P. (2007). 'Trusting Blindly Can Be the Biggest Risk of All': Organised Resistance to Childhood Vaccination in the UK. Sociol. Health Illness 29 (2), 198-215. doi:10.1111/j.1467-9566.2007.00544.x

Hoffman, B. L., Felter, E. M., Chu, K.-H., Shensa, A., Hermann, C., Wolynn, T., et al. (2019). It's Not All about Autism: The Emerging Landscape of Antivaccination Sentiment on Facebook. Vaccine 37 (16), 2216-2223. doi:10.1016/ j.vaccine.2019.03.003

Hulme, M. (2009). Why We Disagree about Climate Change: Understanding Controversy, Inaction and Opportunity. East Anglia: Cambridge University Press. doi:10.1017/cbo9780511841200

Ipsos (2020). Global Attitudes on a COVID-19 Vaccine: Ipsos Survey for the World Economic Forum. Retrieved from: https:/www.ipsos.com/en/global-attitudescovid-19-vaccine-october-2020.

Jarrett, C., Wilson, R., O’Leary, M., Eckersberger, E., and Larson, H. J. (2015). Strategies for Addressing Vaccine Hesitancy - A Systematic Review. Vaccine 33 (34), 4180-4190. doi:10.1016/j.vaccine.2015.04.040

Jasinski, J. (2001). "Rhetorical Situation," in Encyclopedia of Rhetoric. Editor T. O. Sloane (New York: (Oxford University Press), 694-697.

Jenkins, M. C., and Moreno, M. A. (2020). Vaccination Discussion Among Parents on Social media: A Content Analysis of Comments on Parenting Blogs. J. Health Commun. 25 (3), 232-242. doi:10.1080/10810730.2020.1737761

Kasperson, R. E., Renn, O., Slovic, P., Brown, H. S., Emel, J., Goble, R., et al. (1988). The Social Amplification of Risk: A Conceptual Framework. Risk Anal. 8 (2), 177-187. doi:10.1111/j.1539.6924.1988.tb01168.x

Kata, A. (2010). A Postmodern Pandora's Box: Anti-vaccination Misinformation on the Internet. Vaccine 28 (7), 1709-1716. doi:10.1016/j.vaccine.2009.12.022 
Kata, A. (2012). Anti-vaccine Activists, Web 2.0, and the Postmodern Paradigm an Overview of Tactics and Tropes Used Online by the Anti-vaccination Movement. Vaccine 30 (25), 3778-3789. doi:10.1016/j.vaccine.2011.11.112

Kennedy, J. (2019). Populist Politics and Vaccine Hesitancy in Western Europe: an Analysis of National-Level Data. Eur. J. Public Health 29 (3), 512-516. doi:10.1093/eurpub/ckz004

Kestenbaum, L. A., and Feemster, K. A. (2015). Identifying and Addressing Vaccine Hesitancy. Pediatr. Ann. 44 (4), e71-e75. doi:10.3928/0090448120150410-07

Kjeldsen, J., Ihlen, Ø., Just, S. N., and Larsson, A. O. (in press). Expert Ethos and the Strength of Networks: Negotiations of Credibility in Mediated Debate on COVID-19. Health Promotion International. doi:10.1093/ heapro/daab095

Kowalska, M., Gajda, M., Barański, K., and Braczkowska, B. (2019). Sources of Parental Knowledge about the Safety of Vaccinations in Poland. Health Promot. Int. 34 (6), 1191-1199. doi:10.1093/heapro/day096

Larson, H. J., Clarke, R. M., Jarrett, C., Eckersberger, E., Levine, Z., Schulz, W. S., et al. (2018). Measuring Trust in Vaccination: A Systematic Review. Hum. Vaccin. Immunother. 14 (7), 1599-1609. doi:10.1080/21645515.2018.1459252

Larson, H. J., de Figueiredo, A., Xiahong, Z., Schulz, W. S., Verger, P., Johnston, I. G., et al. (2016). The State of Vaccine Confidence 2016: Global Insights through a 67-country Survey. EBioMedicine 12, 295-301. doi:10.1016/ j.ebiom.2016.08.042

Larson, H. J. (2018). The State of Vaccine Confidence. The Lancet 392 (10161), 2244-2246. doi:10.1016/s0140-6736(18)32608-4

Lazarus, J. V., Ratzan, S. C., Palayew, A., Gostin, L. O., Larson, H. J., Rabin, K., et al. (2020). A Global Survey of Potential Acceptance of a COVID-19 Vaccine. Nat. Med. 27, 225-228. doi:10.1038/s41591-020-1124-9

Lee, M. S. W., and Male, M. (2011). Against Medical Advice: the Anti-consumption of Vaccines. J. Consumer Marketing 28 (7), 484-490. doi:10.1108/ 07363761111181464

Luhmann, N. (1993). Risk: A Sociological Theory $\left[{ }^{*}\right.$. United Kingdom: Transaction Publishers.

MacDonald, N. E. and Sage Working Group on Vaccine Hesitancy (2015). Vaccine Hesitancy: Definition, Scope and Determinants. Vaccine 33 (34), 4161-4164. doi:10.1016/j.vaccine.2015.04.036

Machado, A., Santos, A. J., Kislaya, I., Larrauri, A., and Nunes, B. (2020). Understanding Influenza Vaccination Among Portuguese Elderly: The Social Ecological Framework. Health Promot. Int. 35, 1427-1440. doi:10.1093/heapro/ daaa011

McAllister, D. J. (1995). Affect- and Cognition-Based Trust as Foundations for Interpersonal Cooperation in Organizations. Acad. Manag. J. 38 (1), 24-59. doi:10.2307/256727

McCoy, C. A. (2019). Adapting Coercion: How Three Industrialized Nations Manufacture Vaccination Compliance. J. Health Polit. Pol. L. 44, 823-854. doi:10.1215/03616878-7785775

McKinnon, M., and Orthia, L. (2017). Vaccination Communication Strategies: What Have We Learned, and Lost, in 200 years?. Jcom 16 (3), A08. doi:10.22323/2.16030208

Meppelink, C. S., Smit, E. G., Fransen, M. L., and Diviani, N. (2019). "I Was Right about Vaccination": Confirmation Bias and Health Literacy in Online Health Information Seeking. J. Health Commun. 24 (2), 129-140. doi:10.1080/ 10810730.2019.1583701

Mesch, G. S., and Schwirian, K. P. (2015). Confidence in Government and Vaccination Willingness in the USA. Health Promot. Int. 30 (2), 213-221. doi:10.1093/heapro/dau094

Miller, E. (2015). Controversies and Challenges of Vaccination: an Interview with Elizabeth Miller. BMC Med. 13 (1), 267. doi:10.1186/s12916-015-0508-z

Motta, M., Sylvester, S., Callaghan, T., and Lunz-Trujillo, K. (2021). Encouraging COVID-19 Vaccine Uptake through Effective Health Communication. Front. Polit. Sci. 3. doi:10.3389/fpos.2021.630133

Nyhan, B., Reifler, J., Richey, S., and Freed, G. L. (2014). Effective Messages in Vaccine Promotion: a Randomized Trial. Pediatrics 133 (4), e835-e842. doi:10.1542/peds.2013-2365

O'Keefe, D. J. (2016). Persuasion: Theory and Research. 3 ed.. London: Sage.

Offerdal, T. S., Just, S. N., and Ihlen, Ø. (2021). Public Ethos in the Pandemic Rhetorical Situation: Strategies for Building Trust in Authorities' Risk Communication. J. Int. Crisis Risk Commun. Res.
Palenchar, M. J., Heath, R. L., Levenshus, A., and Lemon, L. (2017). Marketplace Commodification of Risk Communication: Consequences for Risk Bearers and Implications for Public Relations. Public Relations Rev. 43 (4), 709-717. doi:10.1016/j.pubrev.2017.05.005

Paterson, P., Meurice, F., Stanberry, L. R., Glismann, S., Rosenthal, S. L., and Larson, H. J. (2016). Vaccine Hesitancy and Healthcare Providers. Vaccine 34 (52), 6700-6706. doi:10.1016/j.vaccine.2016.10.042

Paton, D. (2007). Preparing for Natural Hazards: The Role of Community Trust. Disaster Prev. Management 16 (3), 370-379. doi:10.1108/09653560710758323

Perloff, R. M. (2010). The Dynamics of Persuasion: Communication and Attitudes in the 21st Century. 4 ed.. Mahwah, NJ: Lawrence Erlbaum.

Pivetti, M., Melotti, G., and Mancini, C. (2020). Vaccines and Autism: a Preliminary Qualitative Study on the Beliefs of Concerned Mothers in Italy. Int. J. Qual. Stud. Health Well-being 15 (1), 1754086. doi:10.1080/ 17482631.2020 .1754086

Quinn, S. C., Jamison, A. M., and Freimuth, V. (2021). Communicating Effectively about Emergency Use Authorization and Vaccines in the COVID-19 Pandemic. Am. J. Public Health 111 (3), 355-358. doi:10.2105/AJPH.2020.306036

Rabinowitz, M., Latella, L., Stern, C., and Jost, J. T. (2016). Beliefs about Childhood Vaccination in the United States: Political Ideology, False Consensus, and the Illusion of Uniqueness. PLoS One 11 (7), e0158382. doi:10.1371/ journal.pone. 0158382

Renn, O., and Levine, D. (1990). "Credibility and Trust in Risk Communication," in Communicating Risk to the Public. Editors R. E. Kasperson and P. J. Stallen (Berlin: (Springer), 175-218.

Renn, O. (2009). "Risk Communication: Insights and Requirements for Designing Successful Communication Programs on Health and Environmental Hazards," in Handbook of Risk and Crisis Communication. Editors R. L. Heath and D. O'Hair (New York: (Routledge), 80-98.

Renn, O. (1998). Three Decades of Risk Research: Accomplishments and New Challenges. J. Risk Res. 1 (1), 49-71. doi:10.1080/136698798377321

Rimal, R. N., and Storey, J. D. (2020). Construction of Meaning during a Pandemic: The Forgotten Role of Social Norms. Health Commun. 35, 1732-1734. doi:10.1080/10410236.2020.1838091

Heath, R. L., and O'Hair, D. (2009). Handbook of Risk and Crisis Communication. United Kingdom: Routledge.

Rousseau, D. M., Sitkin, S. B., Burt, R. S., and Camerer, C. (1998). Not so Different after All: A Cross-Discipline View of Trust. Amr 23 (3), 393-404. doi:10.5465/ amr.1998.926617

Sanftenberg, L., Kuehne, F., Anraad, C., Jung-Sievers, C., Dreischulte, T., and Gensichen, J. (2021). Jan 8)Assessing the Impact of Shared Decision Making Processes on Influenza Vaccination Rates in Adult Patients in Outpatient Care: A Systematic Review and Meta-Analysis. Vaccine 39 (2), 185-196. doi:10.1016/ j.vaccine.2020.12.014

Schwarzinger, M., Watson, V., Arwidson, P., Alla, F., and Luchini, S. (2021). COVID-19 Vaccine Hesitancy in a Representative Working-Age Population in France: a Survey experiment Based on Vaccine Characteristics. The Lancet Public Health 6 (4), e210-e221. doi:10.1016/s2468-2667(21)00012-8

Southwell, B. G., Kelly, B. J., Bann, C. M., Squiers, L. B., Ray, S. E., and McCormack, L. A. (2020). Mental Models of Infectious Diseases and Public Understanding of COVID-19 Prevention. Health Commun. 35 (14), 1707-1710. doi:10.1080/ 10410236.2020.1837462

Stephens, K. K., and Malone, P. (2012). "New media for Crisis Communication: Opportunities for Technical Translation, Dialogue, and Stakeholder Responses," in The Handbook of Crisis Communication. Editors W. T. Coombs and S. J. Holladay (Malden, MA: (Wiley-Blackwell), 381-395.

Sun, Y., Chia, S. C., Lu, F., and Oktavianus, J. (2020). The Battle Is on: Factors that Motivate People to Combat Anti-vaccine Misinformation. Health Commun., 1-10. doi:10.1080/10410236.2020.1838108

Thomson, A., Vallée-Tourangeau, G., and Suggs, L. S. (2018). Strategies to Increase Vaccine Acceptance and Uptake: From Behavioral Insights to Context-specific, Culturally-Appropriate, Evidence-Based Communications and Interventions. Vaccine 36 (44), 6457-6458. doi:10.1016/j.vaccine.2018.08.031

Tyson, A., Johnson, C., and Funk, C. (2020). US Public Now Divided over whether to Get COVID-19 Vaccine. Pew Research Center: Science \& Society.

United Nations Office of Disaster Risk Reduction [Unisdr] (2009). UNISDR Terminology on Disaster Risk Reduction. Geneve: United Nations Office for Disaster Risk Reduction. 
Vatz, R. E. (1973). The Myth of the Rhetorical Situation. Philos. Rhetoric 6 (3), 154-161.

Veland, H., and Aven, T. (2013). Risk Communication in the Light of Different Risk Perspectives. Reliability Eng. Syst. Saf. 110 (0), 34-40. Available at: http:// www.sciencedirect.com/science/article/pii/S0951832012001871. doi:10.1016/ j.ress.2012.09.007

Walter, N., Brooks, J. J., Saucier, C. J., and Suresh, S. (2020). Evaluating the Impact of Attempts to Correct Health Misinformation on Social media: A MetaAnalysis. Health Commun., 1-9. doi:10.1080/10410236.2020.1794553

Warren, G. W., and Lofstedt, R. (2021). COVID-19 Vaccine Rollout Risk Communication Strategies in Europe: A Rapid Response. J. Risk Res. 24, 369-379. doi:10.1080/13669877.2020.1870533

Weber, L. R., and Carter, A. I. (2003). The Social Construction of Trust. Amsterdam: Kluwer Academic/Plenum Publishers. doi:10.1007/978-1-4615-0779-6

Wellcome Global Monitor (2018). Attitudes to Vaccines. London: Wellcome Trust. Available at: https://wellcome.ac.uk/reports/wellcome-global-monitor/2018/ chapter-5-attitudes-vaccines/.

Williams, L., Gallant, A. J., Rasmussen, S., Brown Nicholls, L. A., Cogan, N., Deakin, K., et al. (2020). Towards Intervention Development to Increase the Uptake of COVID-19 Vaccination Among Those at High Risk: Outlining Evidence-based and Theoretically Informed Future Intervention Content. Br. J. Health Psychol. 25 (4), 1039-1054. doi:10.1111/bjhp. 12468
Wood, S., and Schulman, K. (2021). Beyond Politics - Promoting Covid-19 Vaccination in the United States. N. Engl. J. Med. 384 (7), e23. doi:10.1056/ nejmms 2033790

World Health Organization [WHO] (2019). Global Influenza Strategy for 20192030. Geneve: WHO.

Xu, Y., Margolin, D., and Niederdeppe, J. (2020). Testing Strategies to Increase Source Credibility through Strategic Message Design in the Context of Vaccination and Vaccine Hesitancy. Health Commun., 1-14. doi:10.1080/ 10410236.2020.1751400

Yaqub, O., Castle-Clarke, S., Sevdalis, N., and Chataway, J. (2014). Attitudes to Vaccination: a Critical Review. Soc. Sci. Med. 112, 1-11. doi:10.1016/ j.socscimed.2014.04.018

Conflict of Interest: The authors declare that the research was conducted in the absence of any commercial or financial relationships that could be construed as a potential conflict of interest.

Copyright $\odot 2021$ Ihlen, Toledano and Just. This is an open-access article distributed under the terms of the Creative Commons Attribution License (CC BY). The use, distribution or reproduction in other forums is permitted, provided the original author(s) and the copyright owner(s) are credited and that the original publication in this journal is cited, in accordance with accepted academic practice. No use, distribution or reproduction is permitted which does not comply with these terms. 